Puput Kusuma Dewi, Ida Bagus Gede Surya Abadi, Ni Wayan Suniasih. (2020). Pengaruh Model Pembelajaran Predict Observe Explain Berbantuan Peta Konsep terhadap Kompetensi Pengetahuan IPS. Jurnal Penelitian dan Pengembangan Pendidikan. Vol. 4 (3) pp. 379-387.

\title{
Pengaruh Model Pembelajaran Predict Observe Explain Berbantuan Peta Konsep terhadap Kompetensi Pengetahuan IPS
}

\author{
Puput Kusuma Dewi ${ }^{*}$, Ida Bagus Gede Surya Abadi², Ni Wayan Suniasih ${ }^{3}$ \\ ${ }^{123}$ Program Studi Pendidikan Guru Sekolah Dasar, Universitas Pendidikan Ganesha, Singaraja, Indonesia
}

\begin{abstract}
Abstrak
Penelitian ini bertujuan untuk menganalisis apakah terdapat pengaruh model pembelajaran Predict Observe Explain berbantuan Peta Konsep terhadap kompetensi pengetahuan IPS siswa kelas IV SD Negeri Gugus Kapten Japa Tahun Ajaran 2019/2020.Jenis penelitian ini eksperimen semu dengan desain penelitian

\section{Kata Kunci:}

Predict Observe Explain,Peta Konsep, Kompetensi Pengetahuan IPS menggunakan nonequivalent control group design.Populasi penelitian meliputi seluruh siswa kelas IV SD Negeri Gugus Kapten Japa yang berjumlah 481siswa.Jumlah SD di Gugus Kapten Japa adalah 6 sekolah dengan jumlah kelas sebanyak 12 kelas. Penentuan sampel menggunakan teknik classster random sampling dengan pengacakan kelas yang telah ada kemudian dilakukan pengundian untuk menentukan kelompok eskperimen dan kelompok kontrol. Sehingga diperoleh kelas IVB SDN 17 Dauh Puri sebagai kelas eksperimen dan kelas IV SDN 4 Dauh Puri sebagai kelas kontrol. Data kompetensi pengetahuan IPS siswa dihimpun melalui tes pilihan ganda biasa. Rata-rata Gain skor ternormalisasikan kelas IV B sebagai kelompok eksperimen yaitu 0.446 lebih dari rata-rata kelas IV kelompok control dengan rata-rata 0.34 .Pengujian hipotesis dianalisis menggunakan uji-t rumus dengan polled varians.Diperoleh nilai $\boldsymbol{t}_{\text {hitung }}=10.18$ dan untuk taraf signifikansi $5 \%$ dengan $\mathrm{dk}=(48+44-2)=90$ diperoleh $t_{\text {tabel }}=1.99$. dengan kriteria $t_{\text {hitung }}>t_{\text {tabel }}$ sehingga dapat disimpulkan $\mathrm{H}_{0}$ ditolak $\mathrm{H}_{\mathrm{a}}$ diterimaHal ini berarti terdapat pengaruh yang signifikan kompetensi pengetahuan IPS kelompok siswa yang dibelajarkan melalui model pembelajaran Predict Observe Explain berbantuan peta konsep dengan kelompok siswa yang dibelajarkan melalui pembelajaran konvensional di kelas IV SD Negeri Gugus Kapten Japa tahun ajaran 2019/2020. Dengan demikian dapat disimpulkan bahwa model pembelajaran Predict Observe Explain berbantuan peta konsepberpengaruhterhadap kompetensi pengetahuan IPS siswa kelas IV SD Negeri Gugus Kapten Japa tahun ajaran 2019/2020.
\end{abstract}

\begin{abstract}
This research aims to find out the effect of predict observe explain learning model assisted with concept map towards students' knowledge competency of social studies for grade 4th students' elementary school in the Kapten Japa cluster academic year 2019/2020. Quasi experimental research is used in this study with using nonequivalent control group designas the research design. The population of the study is all over $4^{\text {th }}$ grade students in Kapten Japa Cluster Elementary Schools which
\end{abstract}

\section{Keywords:}

Predict Observ

Explain Learning Model, Knowledge Competency In Social Studies, Concept Map

\footnotetext{
* Corresponding author.

E-mail Addresses: - kusumadewpuput@gmail.com (Puput Kusuma Dewi)
} 
totaled 481 students. There are six schools with twelve classrooms in Kapten Japa Cluster Elementary Schools. Cluster random sampling technic is used to determine the sample of the research, by doing class randomization and using lottery as the way to determine experimental group and control group. Therefore, it was obtained that IV B class of SDN 17 Dauh Puri as the experimental group and the control group is students of IV class of SDN 4 Dauh Puri. Competency data of students' knowledge in Social Studies are collected through multiple choice test. Gain score average of IV B class as the experimental group is 0.446 which is more than the average of IV class as the control group that is 0.34 . Hypothesis testing is analyzed using t-test formula with polled variance.The result of the analysis is $t_{\text {count }}=10.18$ for $5 \%$ of significance level and $d k=48+44-2=90$ is table $=1.99$, so it was gotten that $t_{\text {count }}>t_{\text {table, }}$ which means $\mathrm{H}_{0}$ is rejected and $\mathrm{H}_{1}$ is accepted. As the result of the research, it can be seen that there is significance effect towards students' knowledge competency in Social Studies by using Predict Observe Explain learning model assisted with concept map and those which using conventional study for grade 4th students elementary school in the Kapten Japa cluster academic year 2019/2020.Thus, it can be concluded that Predict Observe Explain learning model assisted with concept map give effect on $4^{\text {th }}$ grade students' knowledge competency towards the Social Studies in the elementary school of Kapten Japa cluster academic year 2019/2020.

\section{PENDAHULUAN}

Pada era globalisasi ini peningkatan kualitas sumber daya manusia harus menjadi target utama yang segera direalisasikan. Pendidikan merupakan komponen utama dalam hal meningkatkan kualitas sumber daya manusia. Tenaga pendidik dalam hal ini guru menjadi salah satu pemegang peranan yang tak kalah penting. Di dalam pendidikan akan berlangsung suatu proses yang melibatkan guru dengan siswanya untuk mencapai sasaran dan tujuan. Tingkat keberhasilannya sangat dipengaruhi oleh kurikulum yang ada. Di Indonesia telah beberapa kali terjadi perubahan kurikulum. Perubahan kurikulum tersebut tak terelakan dalam proses perkembangan pendidikan. Kurikulum selalu mengalami penyesuaian dengan perkembangan masyarakat. Kurikulum merupakan kunci utama dari keberhasilan suatu pendidikan. Kurikulum yang tidak sesuai dengan perkembangan masyarakat akan mengakibatkan tujuan dan sasaran pendidikan akan sulit untuk dicapai. Undang-Undang Nomor 20 Tahun 2003 tentang Sistem Pendidikan Nasional menyebutkan "kurikulum adalah seperangkat rencana dan pengaturan mengenai tujuan, isi, dan bahan pelajaran serta cara yang digunakan sebagai pedoman penyelenggaraan kegiatan pembelajaran untuk mencapai tujuan pendidikan tertentu".Pendidikan di Indonesia sangat berkaitan erat dengan kurikulum, tanpa kurikulum pendidikan tidak dapat dikatakan sebagai sistem pendidikan yang sempurna.

Pada tingkatan sekolah dasar terdapat salah satu muatan pelajaran yang diintegrasikan di dalam kurikulum 2013 yaitu Ilmu Pengetahuan Sosial (IPS).(Rahmawati et al., 2016)) mengemukakan Ilmu Pengetahuan Sosial (IPS) merupakan salah satu mata pelajaran yang diberikan mulai dari SD/MI/SDLB sampai SMP/MTs/SMPLB. Menurut (Anjarsari et al., 2017)IPS merupakan salah satu mata pelajaran yang diberikan di SD yang mengkaji seperangkat peristiwa, fakta, konsep, dan generalisasi yang berkaitan dengan isu sosial.IPS adalah ilmu pengetahuan yang mengkaji berbagai disiplin ilmu sosial dan humaniora serta kegiatan dasar manusia yang dikemas secara ilmiah dalam rangka memberi wawasan dan pemahaman yang mendalam kepada peserta didik, yakni khususnya ditingkat dasar dan menengah(Antari et al., 2017). Sebagai muatan materi, IPS memiliki garapan yang dipelajari cukup luas. IPS tidak hanya memberikan ilmu pengetahuan semata, tetapi harus berorientasi pada pengembangan keterampilan berpikir kritis, sikap, dan kecakapan-kecakapan dasar siswa yang berpijak pada kenyataan kehidupan sosial kemasyarakatan sehari-hari dan memenuhi kebutuhan bagi kehidupan sosial siswa di masyarakat.

Melalui pembelajaran dengan muatan materi IPS di sekolah, siswa diharapkan dapat membekali pengetahuan dan wawasan tentang konsep dasar ilmu sosial, serta memiliki kepekaan dan kesadaran terhadap masalah sosial di lingkungannya serta dapat memecahkan masalah sosial dengan baik, yang pada akhirnya siswa yang diberikan pembelajaran mengenai muatan materi IPS dapat terbina menjadi warga negara yang baik dan bertanggung jawab. (Parbawa \& Sujana, 2018)menyatakan pembelajaran IPS berperan sebagai pendorong untuk saling pengertian dan persaudaraan antar umat manusia, selain itu juga memusatkan perhatiannya pada hubungan antar manusia dan pemahaman sosial. Sementara itu, 
(Adiwiguna et al., 2016)menyimpulkan pembelajaran IPS di sekolah dasar (SD) menekankan pada pemberian pengalaman langsung untuk mengembangkan kompetensi agar siswa dapat menjelajahi dan memahami manusia dan sejumlah aktivitasnya. Muatan materi IPS memiliki tujuan tersendiri yaitu IPS di sekolah dasar adalah hal yang penting untuk meningkatkan kepekaan siswa dalam lingkungansekitarnya. (Rai Sawitri et al., 2018)menyatakan untuk mencapai tujuan dari pendidikan IPS tersebut maka diperlukan pembelajaran yang menarik bagi siswa, karena dalam muatan materi IPS siswa cenderung bosan dalam belajar, karena banyaknya materi yang harus dipelajari siswa dan materi tersebut bersifat hafalan. Dengan demikian, dalam proses pembelajaran IPS agar dapat bermakna dan menarik bagi siswa dibutuhkan sesuatu yang mampu memotivasi siswa dalam meningkatkan kualitas pendidikan di Indonesia sehingga penyesuaian muatan materi IPS yang diajarkan mampu mengoptimalkan keseluruhan dari komponen yang dimiliki siswa untuk mencapai suatu kompetensi yang diharapkan.

Namun pada kenyataannya proses pembelajaran di sekolah belum menunjukkan hasil yang optimal. Terbukti dari hasil observasi yang dilaksanakan pada tanggal 22 Oktober 2019 diketahui bahwa kini khususnya di SD Negeri Gugus Kapten Japa sudah menerapkan kurikulum 2013. Ditemukan permasalahan menyebabkan rendahnya kompetensi pengetahuan IPS,ini dapat diketahui dari nilai PTS IPS siswa semester I bahwa sejumlah $45 \%$ siswa yang masih mendapatkan nilai dibawah Kriteria Ketuntasan Minimal (KKM) atau siswa yang masih mendapatkan nilai kurang dari 75 hal ini yang sering dialami oleh beberapa siswa,salah satunya siswa kelas IV Gugus Kapten Japa biasanya disebabkan oleh beberapa factor.Faktor-faktor yang mempengaruhi kompetensi pengetahuan siswa yaitu faktor internal dan factor eksternal menurut (Susanto, 2013).Proses pembelajaran yang dilakukan dikelas oleh guru dan siswa sudah berjalan dengan baik namun,siswa menganggap bahwa pelajaran IPS adalah pelajaran yang cenderung pada hapalan dan membosankan, sehingga minat siswa untuk mempelajari IPS kurang. Biasanya saat proses pembelajaran berlangsung siswa kurang mampu dalam mengaitkan pengetahuan yang dimilki dengan pengetahuan baru yang dipelajarinya dan kurangnya siswa mengkomunikasikan. Selain pada diri siswa itu sendiri penyebab bosan atau jenuh bisa juga terjadi pada saat proses pembelajaran itu yang sedang berlangsung,dan ada yang dapat berasal dari luar diri siswa,kemungkinan salah satunya yaitu guru belum merancang pembelajaran yang baik dan secara optimal.

Agar dapat menciptakan suatu suasana agar dalam kegiatan belajar siswa menjadi lebih aktif, diperlukan kemampuan yang nayata dari guru dalam mengkemas suatu materi pembelajaran menjadi lebih menarik agar mampu membangkitkan rasa semangat sehingga siswa tertarik dalam mengikuti proses kegiatan pembelajaran. Berbagai upaya dari guru untuk membantu siswa dalam mendapatkan pengalaman belajar, salah satunya dengan menerapkan suatu model yang inovatif yaitu model PredictObserve-Explain.(Atriyanti, 2015)menyatakan model POE dapat meningkatkan prestasi belajar yang meliputi ranah kognitif, ranah afektif, dan ranah psikomotormemberikan kesempatan bagi siswa. (Puspitasari et al., 2015)menyatakan model pembelajaran POE secara khusus melibatkan peserta didik dalam suatu situasi/masalah, peserta didik harus memberikan dugaan tentang suatu peristiwa fisika sehingga konsepsi awal peserta didik dapat diketahui. Kemudian peserta didik melakukan penyelidikan atas dugaannya, jika dugaannya berbeda dengan apa yang diamati, terjadi konflik antara prediksi dan observasi, maka peserta didik mengalami perubahan konsep dari yang tidak benar menjadi benar.(Surahmadi, 2015)menyatakan model POEmerupakan model yang dikembangkan untuk mengetahui pemahaman siswa mengenai suatu pendekatan konsep dengan pendekatan kontruktivisme. Model ini melatih siswa untuk aktif terlebih dahulu mencari pengetahuan sesuai dengan cara berpikirnya dengan menggunakan sumber-sumber yang dapat memudahkan dalam pemecahan masalah.

(An'nur \& Noor, 2015)menyatakan bahwa model POE dilandasi oleh teori pembelajaran konstruktivisme yakni dengan menggali pengetahuan yang telah diperoleh atau dimiliki siswa sebelumnya dankemudian menginterpretasikannya. Model pembelajaran POEmerupakan salah satu model pembelajaran yang dapat mengaktifkan siswa karena pada model pembelajaran ini peserta didik tidak hanya mendengarkan tetapi juga mengamati peristiwa yang terjadi(Juniari et al., 2014). Model pembelajaran POE menekankan pada siswa yang diharuskan secara aktif membangun pengetahuan dan keterampilannya secara mandiri (Ariyanti et al., 2018).

Beberapa penelitian menemukan bahwa model POE berpengaruh terhadap hasil belajar. Wiguna dalam penelitiannya mengungkapkan bahwa pembelajaran POE memberikan pengalaman langsung pada peserta didik untuk berinteraksi sosial dalam kelompok. (Sumartini, 2017)dalam penelitiannya model pembelajaran POE berperan dalam upaya meningkatkan kemampuan komunikasi siswa. (Jayanti et al., 2016)dalam penelitiannya menyatakan bahwa dengan menggunakanmode; POE yang diberikan dikelas eksperimen mampu meningkatkan kemampuan berpikir tingkat tinggi peserta didik karena model POE merupakan model pembelajaran yang menggunakan tiga langkah utama yaitu predictionatau membuat prediksi, observeatau pengamatan, dan explainationatau penjelasan antara dugaan dengan konsep yang ada. 
Namun perlu dipahami, bahawa dalam proses pembelajaran muatan materi IPS, kompetensi pengetahuan yang didapatkan oleh siswa akan lebih mudah dimengerti dengan bantuan dari media pembelajaran. Salah satu media pembelajaran yaitu, media peta konsep. (Widayani et al., 2014)menyatakan media peta konsep merupakan ilustrasi grafis konkret yang mengindikasikan bagaimana sebuah konsep tunggal dihubungkan ke konsep-konsep lain pada kategori yang sama. Media peta konsep merupakan inovasi yang penting untuk membantu siswa menghasilkan pembelajaran bermakna dalam kelasMedia peta konsep menyediakan bantuan visual konkret, menyajikan pembelajaran lebih ringkas yangdapat mempermudah siswa mengingat dan membantu siswa dalam menyelesaikan kesulitan(Zakiyatun et al., 2017). (Dewi et al., 2014)menyatakan salah satu perangkat pengorganisasian bahan ajar disebut dengan „Concept Map'atau peta konsep. Dalam konteks pengorganisasian bahan ajar guna persiapan mengajar untuk satu semester tertentu, media peta konsep dapat digunakan sebagai cara untuk membangun struktur pengetahuan para guru dalam merencanakan bahan ajar. Peta konsep sebenarnya merupakan suatu bagian dari strategi pengajaran. Sebagai suatu strategi pengajaran, peta konsep menuntut siswa untuk memetakan konsep-konsep kemudian konsep tersebut diilustrasikan sendiri oleh siswa dalam bentuk ilustrasi grafis(Joliarta et al., 2014).

Hal ini didukung berdasarkan penelitian yang dilaksanakan oleh (Cahyani et al., 2014)bahwa penggunan model pembelajaran POE dapat meningkatkan hasil belajar siswa. (Wiguna et al., 2013)dalam penelitiannya menyatakan bahawa Model pembelajaran POE dilihat dari rata-rata hasil belajar siswa yang dibelajarkan dengan model pembelajaran POE dengan lebih besar dari pada rata-rata hasil belajar siswa yang dibelajarkan dengan pembelajaran konvensional, namun masih kurang sumber megenai model pembelajaran Predict Observe Explain berbantuan media peta konsep terhadap kompetensi pengetahuan IPS siswa SD sehingga diperlukan pembuktian secara empiric melalui uji coba atau penelitian. Maka pada kesempatan kali ini penulis melaksnakan penelitian dengan tujuan mengkajiPengaruh Model Pembelajaran Predict Observe ExplainBerbantuan Peta Konsep Terhadap Kompetensi Pengetahuan IPS Siswa SD.

\section{METODE PENELITIAN}

Jenis penelitian ini tergolong eksperimen semu (quasi exsperiment), menggunakan desain yaitu"Non-equivalent Control Group Design". Penelitian ini dilakukan di SD Negeri Gugus Kapten Japa yang terdiri dari enam SD. Populasi pada penelitian ini terdapat 12kelas dengan jumlah 481 siswa. Penentuan sampel dalam penelitian ini menggunakan teknik classster random sampling. Adapun sampel dalam penelitian ini yaitu kelas IVB SD Negeri 17 Dauh Puri sebagai kelompok eksperimen dan kelas IV SD Negeri 4 Dauh Puri sebagai kelompok control. Data yang dikumpulkan pada penelitian ini yakni data kompetensi pengetahuan IPS siswa.

Pengumpulan data penelitian menggunakan metode tes. Tes merupakan cara atau prosedur dalam mengukur dan menilai yang dilakukan dengan pemberian tugas, baik berupa pertanyaan ataupun perintah yang hasilnya akan dapat digambarkan dalam bentuk angka dengan aturan-aturan yang telah ditetapkan (Arikunto, 2015). Tes yang digunakan pada penelitian ini yakni tes pilihan ganda biasa. Dalam tes pilihan ganda biasanya menyediakan alternative kemungkinan jawaban yaitu a,b,c dan d (Arikunto,2015). Pemberian skor dalam bentuk tes objektif untuk setiap butir soal diberikan skor 1 apabila siswa menjawab benar dan skor 0 apabila siswa menjawab salah. Tes pilihan ganda disusun sesuai kisi-kisi soal yang memuat KD dan indicator yang mencangkup 1) Menentukan factor-faktor penyebab keragaman masyarakat Indonesia 2) Menggolongkan keragman suku di Indonesia 3) Menganalisis keragaman suku di Indonesia 4)Mengidentifikasi keragaman bahasa daerah di Indonesia 5) Memaknai dampak penggunaan ragam bahasa daerah terhadap kehidupan masyarakat Indonesia 6) Menentukan nama rumah adat serta daerah asalnya 7)Menganalisis nama pakaian adat serta daerah asalnya 8) Membandingkan keragaman kegiatan ekonomi di masyarakat 9) Mengelompokkan macam-macam hasil aktivitas ekonomi di masyarakat. Sebelum metode ini digunakan sebagai alat untuk mengmpulkan data terlebih dahulu dilakukan pengujian validitas isi dan butir, uji daya beda, uji tingkat kesukaran dan reliabilitas. Metode analisis data yang digunakan dalam penelitian ini yaitu GnS yang diperoleh dari hasil Pretest maupun Postest.Setelah data GnS terkumpul selanjutnya adalah melakukan uji Hipotesisi dengan menggunakan Uji t. sebelum melakukan uji $t$ terlebih dahul melakukan uji prasyarat meliputi uji normalitas dan homogenitas. 


\section{ANALISIS DAN PEMBAHASAN}

Penelitian ini adalah eksperimen dengan memberikan perlakuan pada dua sampel yaitu kelas IVB SD N 17 Dauh Puri menjadi kelas eksperimen dan kelas IV SD N 04 Dauh Puri menjadi kelas kontrol.Pada kelas eksperimen diberikan perlakuan model pembelajaran POE berbantuan Peta Konsepsedangkan pada kelas kontrol diberikan perlakuan model pembelajaran konvensional.Setiap kelas diberikan perlakuan sebanyak 6 kali dan setelahnya diberikan posttest yang bertujuan untuk mendapatkan data nilai dari setiap sampelnya. Berdasarkan perhitungan yang dilakukan diperoleh nilai mean, standar deviasi dan varians dari data posttest kedua kelompok penelitian sebagi berikut.

Tabel 1. Deskripsi data Kompetensi Pengetahuan IPS

\begin{tabular}{lcc}
\hline \multicolumn{1}{c}{ Deskripsi Data } & Kelompok Eksperimen & Kelompok Kontrol \\
\hline $\mathrm{N}$ & 48 & 44 \\
Mean & 0.446 & 0.34 \\
Standar Deviasi & 0.065 & 0.07 \\
Varians & 0.004 & 0.001 \\
\hline
\end{tabular}

Berdasarkan Tabel 1. Didapatkan nilai mean kelompok eksperimen yakni 0.446 dan kelompok control yakni 0.34 . hal ini berarti kelompok eksperimen memilki nilai rata-rata lebih tinggi dari kelompok control. Uji normalitas data dapat dilihat pada Tabel 2. berikut.

Tabel 2. Hasil Uji Normalitas Sebaran Data Gain Skor Ternormalisasi Kelas Eksperimen

\begin{tabular}{ccccc}
\hline Kelas Eksperimen & $\begin{array}{c}\text { Jumlah } \\
\text { Sampel }\end{array}$ & $\begin{array}{c}\text { Nilai } \\
\text { Maksimum }\end{array}$ & $\begin{array}{c}\text { Nilai Tabel } \\
\text { Kolmogrov-smirnov }\end{array}$ & Keterangan \\
\hline $\begin{array}{c}\text { Kelas IVB SD Negeri 17 } \\
\text { Dauh Puri }\end{array}$ & 48 & 0.128 & 0.198 & $\begin{array}{c}\text { N Berdistribusi } \\
\text { Normal }\end{array}$ \\
\hline
\end{tabular}

Berdasarkan Tabel 2. tersebut, diperoleh nilai maksimum $=0.128$ dan nilai Tabel KolmogorovSmirnov untuk taraf signifikansi $5 \%(\alpha=0.05)=0.198$ karena nilai maksimum $<$ nilai tabel KolmogorovSmirnov maka sebaran data gain skor ternormalisasi berdistribusi normal. Perhitungan hasil uji normalitas sebaran data dari gain skor ternormalisasi sampel penelitian kelas eksperimen pada lampiran. Hasil uji normalitas sebaran data dari gain skor ternormalisasi sampel penelitian kelas kontrol disajikan pada Tabel 3. Berikut

Tabel 3. Hasil Uji Normalitas Sebaran Data Gain Skor Ternormalisasi Kelas Kontrol

\begin{tabular}{ccccc}
\hline Kelas Kontrol & $\begin{array}{c}\text { JjJumlah } \\
\text { Sampel }\end{array}$ & Nilai Maksium & $\begin{array}{c}\text { Nilai Tabel } \\
\text { Kolmogrov-smirnov }\end{array}$ & Keterangan \\
\hline $\begin{array}{c}\text { Kelas IV SD Negeri } 4 \\
\text { Dauh Puri }\end{array}$ & 444 & 0.07 & 0.21 & $\begin{array}{c}\text { Berdistribusi } \\
\text { Normal }\end{array}$ \\
\hline
\end{tabular}

Berdasarkan Tabel 3. tersebut, diperoleh nilai maksimum $=0.07$ dan nilai tabel KolmogorovSmirnov untuk taraf signifikansi 5\% $(\alpha=0.05)=0.21$ karena nilai maksimum $<$ nilai tabel KolmogorovSmirnov maka sebaran data gain skor ternormalisasi berdistribusi normal. Uji homogenitas dapat dilihat pada Tabel 4. sebagai berikut.

Tabel 4. Hasil Uji Homogenitas Varians

\begin{tabular}{cccccccc}
\hline Sampel & $\mathbf{S}_{\mathbf{1}}{ }^{2}$ & $\mathbf{S}_{\mathbf{2}}{ }^{\mathbf{2}}$ & $\mathbf{D K}$ & $\mathbf{F}_{\text {hitung }}$ & $\mathbf{F}_{\text {tabel }}$ & Simpulan & Df1 \\
\hline $\begin{array}{c}\text { Kelas IV SDN 17 Dauh Puri dan } \\
\text { kelas IV SDN 4 Dauh Puri }\end{array}$ & 0.001 & 0.004 & 90 & 0,25 & 1.65 & Homogen & 1 \\
\hline
\end{tabular}

Berdasarkan Tabel 4. Dari hasil perhitungan $F_{\text {hitung }}=0,25$, kemudian dibandingkan dengan $F_{\text {tabel }}$ pada taraf signifikansi $5 \%(\mathrm{a}=0.05)$ dengan dk untuk pembilang yaitu 44-1=43 dan dk untuk penyebut yaitu 48-1 =47, sehingga diperoleh $F_{\text {tabel }} 1.65$. maka $F_{\text {hitung }}=0,25<F_{\text {tabel }}=1.65$,sehingga data gainskor ternormalisasi kompetensi pengetahuan IPS antara kelas ekpserimen dan kelas control memiliki varians yang homogen. Hasil uji-t dapat dilihat melalui Tabel 5. sebagai berikut. 
Tabel 5. Rekapitulasi Hasil Uji t Kelompok Sampel Penelitian

\begin{tabular}{clllll}
\hline No & Kelompok Sampel & N & DK & Thitung & t tabel \\
\hline 1 & Eksperimen & 48 & \multirow{2}{*}{10.18} & \multirow{2}{*}{1.99} \\
2 & Kontrol & 44 & & & \\
\hline
\end{tabular}

Berdasarkan hasil uji analisi uji-t data kompetensi pengetahuan IPS siswa yang dibelajarkan dengan model pembelajaran Predict Observe Explain berbantuan Peta Konsep dan yang dibelajarkan dengan pembelajaran konvensional, menghasilkan $t_{\text {hitung }}$ sebesar $10.18>t_{\text {tabel }}$ sebesar 1,99 . Hasil perhitungan tersebut dan hipotesis alternatif $\left(\mathrm{H}_{1}\right)$ diterima dan $\mathrm{H}_{0}$ ditolak.

Dari hasil analisis yang telah dilaksankan dan dibuktikan ketika proses pelaksanaan pembelajaran berlangsung, pada kelas eksperimen yang diberikan perlakuan berupa model pembelajaran POE berbantuan media peta konsep siswa dapat menjadi lebih aktif karena terlibat secara langsung dalam suatu proses baik mengemukakan sebuah gagasan maupun dalam pengamatan langsung, hal ini pastinya akan lebih bermakna untuk siswa dan pemahaman siswa akan lebih membekas dalam ingatan siswa. Siswa akan lebih bersemangat dalam proses pembelajaran IPS dilihat dari segi afektif, hal ini disebabkan karena kegiatan siswa yang membuat partisipasi siswa aktif selama kegiatan.

Selain itu pada penelitian ini juga dibantu dengan adanya peta konsep. Mata pelajaran IPS merupakan pelajaran yang menuntut siswa untuk banyak membaca agar mengetahui materi dari pelajaran tersebut. Bacaan-bacaan yang terlalu banyak itulah yang kadang membuat siswa bingung untuk mengetahui konsep dan inti dari pembelajaran yang ingin guru sampaikan. Sehingga dengan pemberian sebuah peta konsep siswa akan lebih mudah mengetahui secara garis besar materi pembelajaran IPS tersebut. Dalam pelajaran IPS, peta konsep sangat membantu.Peta konsep membantu siswa untuk mengilustrasikan secara nyata konsep-konsep yang bersifat abstrak dengan membuat peta konsep yang sistematis. Untuk menciptakan kegiatan pembelajaran yang bermakna, siswa harus diajak untuk mengaitkan konsep yang telah dipelajari dengan konsep yang baru dipelajari secara relevan. Saat siswa berlatih membuat peta konsep,mereka mencari inti sari dari bacaan, sehingga secara otomatis siswa membaca dengan seksama.Selain menjadi media pembelajaran yang mempermudah siswa memahami konsep-konsep yang dipelajari, peta konsep juga dapat membantu baik siswa ataupun guru sebagai media yang menjadi tolak ukur evaluasi pembelajaran.

Hasil tersebut didukung oleh beberapa teori dari (Fahrinnisak, 2018)yang menyatakan bahawa pembelajaran dengan menggunakan model pembelajaran Predict-Observe-Explain (POE akan memberikan kesempatan kepada siswa untuk berperan aktif dalam kegiatan belajar yang dimulai dengan penyajian masalah, siswa diarahkan untuk memberikan dugaan sementara terhadap kemungkinan yang akan terjadi, dilanjutkan dengan observasi atau pengamatan langsung terhadap masalah, kemudian dibuktikan dengan melakukan percobaan untuk menemukan kebenaran dari dugaan sementara dalam bentuk penjelasan. Hal tersebut dibuktikan pada hasil penelitian oleh (Fitriana, 2019)yang menyebutkan bahwa terdapat pengaruh dari model POE terhadap pemahaman konsep siswa. (Abdawiyah et al., 2016)juga menyatakan bahwa terdapat pengaruh dari model POE terhadap konsep dan pemahaman keterampilan proses siswa.

Berdasarkan hal tersebut, dengan menerapkan model POE berbantuan peta konsep dapat memberikan pengaruh terhadap kompetensi pengetahuan IPS siswa. Pada materi pembelajaran yang sama, model Predict Observe Explain berbantuan peta konsep dan pembelajaran konvensional di bandingkan hasilnya untuk menentukan pembelajaran yang memberikan pengaruh lebih baik terhadap kompetensi pengetahuan IPS siswa, serta dalam proses pembelajaran siswa memperoleh pengalaman berpikir yang lebih fokus dan terarah sesuai dengan tujuan pembelajaran. Pada pembelajaran POE tahap eksplorasi dan pembentukan konsep guru dapat mengarahkan siswa membuat peta konsep untuk menemukan sendiri konsep yang sedang dipelajari berdasarkan hasil menggali observasi yang sudah dilakukan siswa.Pembuatan peta konsep dilakukan dengan membuat catatan yang kreatif dan efektif menggunakan garis dan warna.. Adapun tahapan pelaksanaan model POE terdiri dari 3 tahapan yaitu Predict, Observe,Explain(Muna, 2017).

Selain itu, kelebihan model POE Siswa lebih kreatif dalam mengemukakan gagasan prediksi, dimana hal ini akan membantu guru untuk mengetahui konsep atau pengetahuan awal siswa,(2)Meningkatkan rasaa keingintahuan siswa sehingga siswa dengan mandiri akan melakukan pengamatan untuk menguji hasil dugaan atau prediksi, (3) Kegiatan guru menjelaskan secara verbal akan dialihkan dengan kegiatan siswa melakukan pengamatan untuk menguji prediksi yang telah dibuat untuk mengetahui kebeneran konsep, (4) Dikarenakan model pembelajaran ini menuntu siswa untuk melakukan suatu eksperimen, maka siswa akan mendapatkan pengalaman belajar yang tidak monoton sehingga kegiatan pembelajaran lebih aktif dan menyenangkan, (5) Melalui kegiatan pengamatan siswa 
akan mendapatkan pengalaman belajara yang bermakna untuk kehidupan nyata, karena siswa dapat mebandingkan prediksi mereka yang berdasarkan teori dengan aplikasi nyata yang ada dikehidupan bermasyrakat (Yupani et al., 2013).

Hasil penelitian ini diperkuat dengan penelitian yang dilakukan oleh (Sudiadnyani et al., 2013)yang memperoleh hasil penelitiannya berkesimpulan bahwa pemahaman siswa kelas IV terhadap konsep pembelajaran akan meningkat jika menerapkan model POE sebagai model pembelajaran di kelas dibandingkan dengan siswa yang mendapat model pembelaran konvensional. Begitu juga dengan (Sastrawan et al., 2014)menemukan bahwa prestasi belajar IPS siswa kelas IV menggunakan model POE sangat meningkat.

Adapun implikasi yang didapatkan dalam penemuan-penemuan tersebut menunjukkan bahwa dari pembelajaran dengan menggunakan model Predict Observe Explain berbantuan Peta Konsep ini adalah siswa lebih bisa memahami pembelajaran IPS secara garis besar dan mengkhusus pada inti materi yang dipelajari, karena dengan pembelajaran ini siswa diberikan peta konsep yang berisikan inti-inti materi yang akan mereka pelajari selama proses pembelajaran berlangsung. Selain berdampak pada peningkatan kompetensi pengetahuan IPS, dengan diterapkannya model model Predict Observe Explain berbantuan Peta Konsep siswa dapat merumuskan suatu dugaan terhadap suatu permasalahan karena pada model ini, dilangkah awal siswa diajak menduga (Predict) sebab dan akibat terjadinya suatu permasalahan berdasarkan pengetahuan yang mereka miliki. Dengan hal tersebut siswa akan mulai belajar mengindetifikasi suatu permasalahan dan pada akhirnya mereka dan menemukan solusi dari permasalahan tersebut. Setelah menduga dan mengetahui sebab atau akibat dari suatu pemasalahan siswa diajak mengobservasi pemasalahan yang mereka duga. Dengan begitu berimplikasi kepada motoric dan sensorik siswa untuk mencari kebenaran suatu dugaan yang mereka kemukakan terhadap suatu permasalahan. Dan yang terakhir siswa diajakan menjelaskan permasalahan yang ia temukan dan hasil obeservasi yang mereka temukan. Hal ini akan berguna untuk melatih kemampuan mereka dalam mengemukankan kembali hasil temuannya. Sehingga akan berimplikasi pada keterampilan public speaking siswa itu sendiri.

\section{KESIMPULAN}

Berdasarkan analisis data serta pembahasan maka terdapat perbedaan yang signifikan Kompetensi Pengetahuan IPS antara kelompok yang dibelajarkan dengan model pembelajaran POE berbantuan Peta Konsep dengan kelompok yang dibelajarkan melalui pembelajaran konvensional pada kelas IV SD Negeri Gugus Kapten Japa. Hal ini berartidisimpulkan bahwa terdapat pengaruh yang signifikan model pembelajaran POE berbantuan Peta Konsep terhadap kompetensi pengetahuan IPS siswa kelas IV. Sesuai temuan penelitian ini, untuk guru, kepala sekolah serta peneliti lainnya agar lebih memperkaya diri dengan memiliki banyak pilihan model pembelajaran sehingga nantinya dapat memaksimalkan pencapaian tujuan pembelajaran serta mengaplikasikan model POE berbantuan Peta Konsep pada proses pembelajaran IPS sehingga dapat mewujudkan pembelajaran yang mudah dipahami dan menyenangkan bagi siswa. Guru bisa menjadikan penelitian ini sebagai refrensi dalam menciptakan suasana pembelajaran disekolah agar lebih menarik dan tentunya siswa lebih mampu memahami dengan baik setiap materi yang disampaikan oleh guru. Penelitian ini juga bisa menjadi refrensi bagi peneliti lain saat mencari sumber-sumber yang dapat diperoleh dari penelitian ini. Bagi siswa agar lebih aktif dalam mengikuti pembelajaran disekolah. Bagi Guru agar dapat menerapkan untuk meningkatkan kemampuan professional guru dalam proses pembelajaran dikelas, khususnya untuk membantu siswa dalam mengelola secara efektif pembelajarannya sendiri. Bagi Kepala Sekolah dari hasil penelitian ini dapat digunakan sebagai tolak ukur bagi sekolah agar tercapainya mutu pendidikan yang lebih optimal di dalam sekolah. Bagi Peneliti lain hasil penelitian ini dapat digunakan sebagai bahan pertimbangan dan refrensi dalam melakukan penelitian.

\section{DAFTAR PUSTAKA}

Abdawiyah, R., Roektiningroem, E., \& Wibowo, widodo S. (2016). Pengaruh Model Pembelajaran Poe (Predictobserve-Explain) Terhadap Pemahaman Konsep Dan Keterampilan Proses Ipa Peserta Didik Kelas Viii Smp N 1 Banguntapan. Journal of Chemical Information and Modeling, 5(4), 16891699. http://journal.student.uny.ac.id/ojs/index.php/ipa/article/view/1097

Adiwiguna, I. W., Wiarta, I. W., Bagus, I., \& Surya, G. (2016). Model Pembelajaran Role Playing Berbasis Pendekatan Saintifik Berpengaruhterhadap Penguasaan Kompetensi Pengetahuan Ips. MIMBAR PGSD Undiksha, 4(1). https://doi.org/http://dx.doi.org/10.23887/jjpgsd.v4i1.7253 
An'nur, S., \& Noor, A. F. (2015). Perbedaan Hasil Belajar antara yang Menggunakan Model Pembelajaran POE (Prediction Observation Explanation) dan EIA (Exploration Introduction Application) pada Siswa Kelas XI IPA SMA Negeri 4 Banjarmasin. Jurnal Inovasi Dan Pembelajaran Fisika, 2(2), 185193. https://ejournal.unsri.ac.id/index.php/jipf/article/view/2622

Anjarsari, K. Y., Suniasih, N. W., \& Sujana, I. W. (2017). Pengaruh Model Pembelajaran Talking Chips Berbasis Tri Hita Karana Terhadap Kompetensi Pengetahuan Ips. MIMBAR PGSD Undiksha, 5(2). https://doi.org/10.23887/jjpgsd.v5i2.10659

Antari, N. L. P. Y., Wiarta, I. W., \& Putra, M. (2017). Pengaruh Model Pembelajaran Kooperatif Tipe Two Stay Two Stray (Tsts) Berbantuan Multimedia Terhadap Kompetensi Pengetahuan Ips Siswa Kelas V Sd Gugus Letda Made Putra. MIMBAR PGSD Undiksha, 5(2). https://doi.org/10.23887/jjpgsd.v5i2.10650

Ariyanti, L., Utami, B., \& VH, E. S. (2018). Penerapan Model Pembelajaran Predict Observe Explain (POE) Dilengkapi LKS Berbasis Drill and Practice untuk Meningkatkan Keaktifan dan Prestasi Belajar Siswa pada Materi Hidrolisis Garam Kelas XI IPA 3 Semester Genap SMA N 2 Karanganyar. Jurnal Pendidikan Kimia, 7(1), 86. https://doi.org/10.20961/jpkim.v7i1.24570

Atriyanti, Y. (2015). Penerapan Model Pembelajaran Poe Untuk Meningkatkan Ketercapaian Kompetensi Dasar Siswa. School Science and Mathematics, 4(1), 133-139. https://doi.org/10.1111/j.19498594.1902.tb00418.x

Cahyani, N. W., Agung, A. A. G., \& Magunayasa, I. D. (2014). Pengaruh Model POE dan Minat Belajar Terhadap Hasil Belajar IPA. Jurnal Mimbar PGSD Universitas Pendidikan Ghanesha, 2(1). https://ejournal.undiksha.ac.id/index.php/JJPGSD/article/view/3104

Dewi, N. P. D. U., Ganing, N. N., \& Asri, I. G. A. A. S. (2014). Model Pembelajaran Kooperatif Tipe Tai Berbantuan Media Peta Konsep Terhadap Hasil Belajar Pkn Sd. MIMBAR PGSD Undiksha, 2(29). https://doi.org/http://dx.doi.org/10.23887/jjpgsd.v2i1.1885

Fahrinnisak. (2018). Penerapan Model Pembelajaran Poe (Predict, Observe, Explain) Terhadap Hasil Belajar Siswa Kelas V Di Sdn Pangarangan Iii Sumenep. Alpen: Jurnal Pendidikan Dasar, 2(1). https://doi.org/10.24929/alpen.v2i1.13

Fitriana, A. W. (2019). Pengaruh Model Pembelajaran Poe (Predict-Observe-Explain) Berbantu Metode Eksperimen Terhadap Pemahaman Konsep Fisika Siswa Kelas Xi Ipa. Journal of Chemical Information and Modeling, 53(9), 1689-1699. https://doi.org/10.1017/CB09781107415324.004

Jayanti, R. D., Romlah, \& Antomi, S. (2016). Efektivitas Pembelajaran Fisika Model Problem Based Learning (Pbl) Melalui Metode Poe Terhadap Kemampuan Berpikir Tingkat Tinggi Peserta Didik. 208-214. http://repository.radenintan.ac.id/3314/

Joliarta, K., Dantes, N., Arini, N. W., \& Ganesha, U. P. (2014). Pengaruh Penggunaan Media Peta Konsep Terhadap Kemampuan Menulis Cerpen Siswa Kelas V Sd Kecamatan Buleleng. 2(1). https://doi.org/http://dx.doi.org/10.23887/jjpgsd.v2i1.1947

Juniari, N. K., Kusmariyatni, N., \& I Gede Margunayasa. (2014). Pengaruh Model Pembelajaran Poe Dan Motivasi Belajar Terhadap Hasil Belajar Ipa Siswa Kelas V Sd. Mimbar PGSD, 2(1), 434-439. https://ejournal.undiksha.ac.id/index.php/JJPGSD/article/view/3107

Muna, I. A. (2017). Model Pembelajaran POE (Predict-Observe-Explain) dalam Meningkatkan Pemahaman Konsep dan Keterampilan Proses IPA. El-Wasathiya: Jurnal Studi Agama, 5(1), 74-91. https://core.ac.uk/download/pdf/231311801.pdf

Parbawa, I. G. N. M. A., \& Sujana, I. W. (2018). Pengaruh Model Pembelajaran Visual Auditory Kinestetik dan Motivasi Belajar terhadap Kompetensi Pengetahuan IPS Siswa Kelas IV. Ilmiah Sekolah Dasar, 2(1), 68-72. https://ejournal.undiksha.ac.id/index.php/JISD/article/view/13896 
Puspitasari, R., Lesmono, A., \& Prihandono, T. (2015). Pengaruh Model Pembelajaran Poe (Prediction, Observation and Explanation) Disertai Media Audiovisual Terhadap Keterampilan Kerja Ilmiah Dan Hasil Belajar Siswa Dalam Pembelajaran Ipa-Fisika Di Smp. Jurnal Pembelajaran Fisika, 4(3), 211-218-218. https://jurnal.unej.ac.id/index.php/JPF/article/view/2639

Rahmawati, A. D., Ganing, N. N., \& Sujana, I. W. (2016). Pengaruh Pendekatan Saintifik Berbasis Portofolio Terhadap Penguasaan Kompetensi Pengetahuan Ips Ditinjau Dari Kepercayaan Diri. MIMBAR PGSD Undiksha, 4(1). https://doi.org/10.23887/jjpgsd.v4i1.7014

Rai Sawitri, N. N., Suniasih, N. W., \& Sujana, I. W. (2018). Pengaruh Model Pembelajaran Circ Berbasis Karakter Terhadap Kompetensi Pengetahuan Ips Siswa. Mimbar Ilmu, 23(2), 129-135. https://doi.org/10.23887/mi.v23i2.16420

Sastrawan, P. E., Tegeh, I. M., \& Raga, G. (2014). Pengaruh Metode Predict Observe Explain Terhadap Prestasi Belajar Ips Siswa Kelas Iv Sd Di Gugus Ii Santalia Kecamatan Kubutambahan. MIMBAR PGSD Undiksha, 2(1). https://doi.org/http://dx.doi.org/10.23887/jjpgsd.v2i1.2552

Sudiadnyani, P., Sudana, D. N., \& Garminah, N. N. (2013). Pengaruh Model Pembelajaran Predict-ObserveExplain (POE) terhadap Pemahaman Konsep IPA Siswa Kelas IV SD Kelurahan Banyuasri. Mimbar PGSD Undiksha, 1(1), 1-10. https://doi.org/http://dx.doi.org/10.23887/jjpgsd.v1i1.890

Sumartini, T. S. (2017). Meningkatan Kemampuan Komunikasi Matematis Siswa Melalui Model Pembelajaran Predict Observe Explanation. JES-MAT (Jurnal Edukasi Dan Sains Matematika), 3(2), 167. https://doi.org/10.25134/jes-mat.v3i2.689

Surahmadi, B. (2015). Pengaruh Model Pembelajaran POE ( Predict-Observe-Explain ) Ditinjau Dari Motivasi Belajar dan Pengetahuan Awal Terhadap Hasil Belajar IPA Peserta Didik Kelas VII SMP N 1 Temanggung. April, 66-69. https://pdfs.semanticscholar.org/7d37/f69917288a81ec006d3e7a9e5735d4b2ec4a.pdf

Susanto, A. (2013). Teori Belajar \& Pembelajaran. Kencana.

Widayani, P. Y., Putra, I. M., \& Ganing, N. N. (2014). Pengaruh Student Facilitator And Explaining Berbantuan Peta Konsep Terhadap Hasil Belajar Pkn Kelas V Sd Gugus Igusti Ngurah Rai. Jurnal Mimbar PGSD Universitas Pendidikan Ganesha, 2(1). https://ejournal.undiksha.ac.id/index.php/JJPGSD/article/view/2152

Wiguna, C. S., Sumaatmadja, N., \& Ningrum, E. (2013). Pengaruh Model Pembelajaran Poe Terhadap Pemahaman Konsep Dan Kemampuan Berpikir Kreatif Peserta Didik. Jurnal Geografi, 13(1), 3041. https://ejournal.upi.edu/index.php/gea/article/view/3306

Yupani, N. P. E., Garminah, N. N., \& Mahadewi, L. P. P. (2013). Pengaruh Model Pembelajaran PredictObserve-Explain (POE) Berbantuan Materi Bermuatan Kearifan Lokal terhadap Hasil Belajar IPA Siswa Kelas IV. MIMBAR PGSD Undiksha, https://doi.org/http://dx.doi.org/10.23887/jjpgsd.v1i1.1363

Zakiyatun, C., Cawang, C., \& Kurniawan, R. A. (2017). Pengaruh Media Peta Konsep Dalam Model Pembelajaran Kooperatif Tipe Numbered Heads Together (Nht) Terhadap Hasil Belajar Dan Daya Ingat Siswa Pada Materi Hidrolisis Garam Kelas Xi Mipa Sma Negeri 7 Pontianak. AR-RAZI Jurnal Ilmiah, 5(2). https://doi.org/10.29406/arz.v5i2.629 